\title{
Relationship between Outpatients' Visit Time and Physicians' Prescription Quality in Teaching Hospitals of Ahvaz: 2015
}

\author{
Farzad Faraji Khiavi ${ }^{1}$, Mohammad Qolipour ${ }^{2}$, Davoud Afshar Farouji ${ }^{3} \&$ Iman Mirr $^{4}$ \\ ${ }^{1}$ Department of Health Services Management, School of Health, Ahvaz Jundishapur University of Medical \\ Sciences, Ahvaz, Iran \\ ${ }^{2}$ Student Research Committee, Department of Health Services Management, Ahvaz Jundishapur University of \\ Medical Sciences, Ahvaz, Iran \\ ${ }^{3}$ Department of Medicinal Chemistry, School of Pharmacy, Ahvaz Jundishapur University of Medical Sciences, \\ Ahvaz, Iran \\ ${ }^{4}$ Department of Biostatistics and Epidemiology, School of Health, Ahvaz Jundishapur University of Medical \\ Sciences, Ahvaz, Iran \\ Correspondence: Mohammad Qolipour, Student Research Committee, Department of Health Services \\ Management, Ahvaz Jundishapur University of Medical Sciences, Ahvaz, Iran. Tel: 98-939-013-0890. E-mail: \\ Qolipour.m@ajums.ac.ir
}

Received: November 19, 2015

Accepted: January 14, 2016 Online Published: February 29, 2016

doi:10.5539/gjhs.v8n11p83

URL: http://dx.doi.org/10.5539/gjhs.v8n11p83

\begin{abstract}
Background: Examination time is a key factor determining the relative value of clinical physicians' examination and care quality. Whereas commitment to standard prescription principles by physicians increases the likelihood of proper treatment, its effectiveness and patients' improvement. This study aimed to determine the relationship between outpatients' examination time and physicians prescribing quality in teaching hospitals of Ahvaz.

Methods: This cross-sectional study was conducted in 550 outpatients who visited teaching hospitals of Ahvaz in 2015. The quality of the prescriptions was assessed by WHO checklist. Each prescription was scored with a score range from 0 to 21 , they were divided into four equal score categories including low $(0-5.25)$, low intermediate (5.26-10.5), high intermediate (10.5-15.75) and good (15.76-21) and using correlation and regression was analyzed.

Results: The total mean of examination time and commitment to prescription principles was $4.88 \pm 0.12$ min and $15.92 \pm 1.14$, respectively. Correlation coefficients between outpatients' examination time and dimensions of "legibility", "pharmaceutical form" and "medical orders", and the total quality of prescription were significant $(p<0.005)$. The relationship between examination time and prescription quality confirmed with the fitting linear regression model. Increase per minute in patient's examination by a physician, which is about 0.33 points, was added to the basic quality scores of prescription.
\end{abstract}

Conclusion: There was a relationship between Examination time and dimensions of legibility, pharmaceutical form, and medical order. Considering commitment to standard prescription principles, examination time, which was declared by the Health Sector Evolution Guideline, improve physicians' prescription quality and quality of provided services of hospitals. Therefore, providing an internet schedule for examination will be extremely helpful in organizing physicians' examination.

Keywords: outpatients, prescriptions, examination time

\section{Introduction}

Examination time is the period between when a patient enters and leaves the examination room. It also covers the next visit of the patient to check the results of the laboratory and imaging tests is part of the examination time (Khouri, Changizi, Pourreza, \& Zeinali, 2009). It is a key factor which determines the relative value of clinical physicians' examination and care quality (Bayati, Soltanian, Kamali, \& Shamsi, 2011; Campbell, Ramsay, \& Green, 2001).

The results of this study, which assessed the role of participative management in outpatients' waiting time, visit 
time and satisfaction at the Tehran Razi Hospital, showed that the examination time and patients' satisfaction with hospital services were $4.34 \mathrm{~min}$ and 3.37 out of 5 scores (weak scale), respectively; after the intervention, they were $5.6 \mathrm{~min}$ and 3.84 out of 5 scores (medium scale) (Mosadeghrad, 2004). The results of a study in England showed that specialists of clinics devoted $37 \mathrm{~min}$ to new patients and $29 \mathrm{~min}$ to patients visiting again, which is moderate. Also, in public clinics, physicians spent 23 min for new patients (Benson \& Burnet, 2001).

In the health sector, in terms of importance of services and its relationship with human life, quality improvement and assurance, maintenance, improvement and promotion of health services, and response to the needs of people are demands of the society and are considered as some of the development indicators of a country (Shadpour, 2006; Tabibi, Gohari, Shahri, \& Aghababa, 2011). Service quality is the difference factor and competitive advantage that many service providing organizations have. Today, providing high quality services by maintaining high levels of quality is essential for the success of service organizations. Hence, the achievement of service quality assurance by health authorities is inevitable (Tabibi et al., 2011). However, the service quality of the health system is assessed in different ways and many studies on quality attempt to use valid and repeatable tools (Ford, Bach, \& Fottler, 1997; Ladhari, 2009).

During the fourth program of Health Sector Evolution Guideline in Iranian Hospitals in affiliation with the Treatment Deputy, Ministry of Health, Treatment and Medical Education (improving the quality of visit services), commitment to standard prescription principles and examination time by physicians was declared as the component which improves the quality of outpatient consultant services, and the standard of examination time in the first year of the program implementation was 8 patients per hour for all physicians and 6 patients per hour for psychiatrists in government hospitals. In 2015, which is the second year of implementation, 15 min for general practitioner, $20 \mathrm{~min}$ for specialist, $25 \mathrm{~min}$ for specialty and $30 \mathrm{~min}$ for psychiatrist per patient was declared (Shah, Aslam, \& Avery, 2001).

Prescription is the last stage of doctor-patient relationship and is considered as a medical record (Zeraati, Araghchian, Esna'Ashari, Saneii, \& Torkashevand, 2014). Commitment to standard prescription principles by physicians increases the likelihood of proper treatment, its effectiveness and patients' improvement, while non commitment to standard prescription principles leads to improper use of drugs, non-use of prescribed drugs, drug interactions and increased possible side effects. Majority of the adverse drug effects (the most common cause of patients' injuries) (49 to 56\%), have been reported in the prescribing stage. Medication errors are the most frequent and most preventable cause of medical errors (Bobb et al., 2004; Jeddi, Jeddi, \& Mofrad, 2011). Studies in Iran showed that in interns' prescription, $8.7-21 \%$ of medication order was illegible; $74.1 \%$ of the order of drug use, $13.19 \%$ of drug number, $84.7 \%$ of medication way and instruction for drug use were not written (Motamed et al., 2006).

With regards to visit, increase in service quality is the priority of the Health Sector Evolution Guideline in Treatment, Ministry of Health, Treatment and Medical Education and commitment to visiting standard time by physicians is essential. Also, teaching hospitals in Ahvaz are considered as the most important care centres in the south west of Iran. Hence, this study aimed to determine the relationship between outpatients' examination time and physicians' prescription quality in teaching hospitals of Ahvaz in 2015.

\section{Methods}

This cross-sectional and descriptive study was conducted in 2015 (from 09 April to 20 May). The study population included outpatients who visited clinics in teaching hospitals of Ahvaz. To determine the sample size, Cochran sampling formula with values $p=0.5, q=0.5, z=1.96$ and $d=0.2$ was used. The sample size (n) was 550 patients, including 23.05 to avoid loss of data; the sample size was considered as 25 patients for each 22 specialists in the clinic. Selected physicians for this study were 22 different medical specialists in clinics and emergency, and general practitioners of teaching hospitals of Ahvaz University of Medical Sciences (areas of specialty includes Endocrinology, Otorhinolaryngology, Cardiology, Urology, Gastroenterology, Pulmonology, Pediatrics, Internal, Toxicology, Dermatology, Neurology, General Practitioner, General Surgery, Infectious Disease, Genetics, Orthopedics, Hematology, Ophthalmology, Neurosurgery, Psychiatry, Obstetrics And Gynecology and Cardiovascular Surgery). Examination time per patient was measured without informing the physician about the main purpose of the study for simple randomization. Immediately after the patient had left the examination room, a graduate student in the field of medicinal chemistry, assessed the patient's prescription. A data gathering form was developed based on WHO recommendations on commitment to principles of prescription writing, in each prescription, which are related to issues in drug form (1. Proper spelling; 2. dosage form; 3. proper spelling of dosage form); medical order (4. the number of drugs; 5 . drug dosage; 6. the order of drug use in Latin; 7. medical recommendations; 8. duration of drug use; 9. instruction on 
drug use; 10. drug use frequency); physician's information, 11. name; 12. family name; 13. specialty; 14. medical system code; 15. signature; patient's information (16. name; 17. family name; 18. age; 19. gender; 20. weight) and legibility (as the $21^{\text {th }}$ item), were analysed for each drug. If the handwriting was comprehensible without referring to any other person or the physician himself, it was considered as eligible. Each of the 21 mentioned items had a score of either 0 or 1 and the total score for each prescription was in the range of 0 to 21 and was recorded on the preparation checklist (Jeddi et al., 2011).

The scores were analyzed using descriptive statistics (frequency; SPSS16 and Excel 2007) and categorized into tables. For better analysis, the scores were divided into four equal score categories including weak (0-5.25), low intermediate (5.26-10.5), high intermediate (10.5-15.75) and good (15.76-21). The relationship between time of examination and quality dimensions of prescription was assessed by statistical tests. Data was analyzed by descriptive statistic and linear regression model.

\section{Results}

The drug mean per prescription was 3.48 and a total of 1918 drugs were prescribed. Among all the 22 medical specialists, cardiologists and geneticists had the highest and the lowest drug mean per prescription (5.2 and 2 drugs, respectively). Moreover, 685 (35.71\%) prescriptions were for male patients and $1233(64.29 \%)$ for female patients; $21.10 \%$ of the patients were under 20 years, $32.20 \%$ were between 20 and 40 years and $46.70 \%$ were above 40 years. Table 1 shows the minimum and maximum percentage of commitment to prescription principle based on specialty which is the correct dimensions (commitment\%) per 25 prescriptions.

Table 1. Minimum and maximum percentage of commitment to prescription principles in different specialties

\begin{tabular}{llll}
\hline Prescription principles & Min/Max & Specialty & Percentage* $^{*}$ \\
\hline \multirow{2}{*}{ Legibility } & Min & Infectious Disease & 60 \\
& Max & Psychiatry & 88 \\
\hline \multirow{2}{*}{ Pharmaceutical form } & Min & Toxicology & 33.33 \\
& Max & Otorhinolaryngology & 80 \\
\hline \multirow{2}{*}{ Medical order } & Min & Toxicology & 57.14 \\
& Max & Pulmonology & 75.43 \\
\multirow{2}{*}{ Physician identifying information } & Min & Gastroenterology & 91.2 \\
& Max & Psychiatry & 100 \\
\hline \multirow{2}{*}{ Patient identifying information } & Min & Toxicology & 80 \\
& Max & Dermatology & 84 \\
\hline \multirow{2}{*}{ Total } & Min & Toxicology & 68.34 \\
& Max & Psychiatry & 83.24 \\
\hline
\end{tabular}

*percentage of commitment to prescription principle.

Average percentage for considering prescription principles in all specialties was calculated 73.30 for legibility, 53.82 for pharmaceutical form, 66.82 for medical order, 98.80 for physician identifying information, and 80.36 for patient identifying information. Total average of considering prescription principles for all studied specialties was 74.47 percent.

Measuring examination time of 22 specialists, determined the highest and lowest mean of outpatients' examination time which is related to the psychiatrist $(8.61 \mathrm{~min})$ and general practitioner $(3.40 \mathrm{~min})$, respectively. The highest and lowest mean of the quality of the prescriptions was related to the psychiatrist (17.28 \pm 0.51$)$ and toxicologist (14.68 \pm 0.76 ), respectively (Table 2 ). 
Table 2. Mean of outpatients' examination time and commitment to prescription principles based on specialty

\begin{tabular}{|c|c|c|}
\hline Specialty & $\begin{array}{l}\text { Commitment to prescription principles } \\
\text { C.I for Mean }\end{array}$ & $\begin{array}{l}\text { Examination time } \\
\text { C.I for Mean }\end{array}$ \\
\hline Endocrinology & $16.56 \pm 0.53$ & $4.75 \pm 0.22$ \\
\hline Otorhinolaryngology & $17.27 \pm 0.51$ & $5.71 \pm 0.38$ \\
\hline Cardiology & $16.92 \pm 0.80$ & $6.21 \pm 0.22$ \\
\hline Urology & $16.88 \pm 0.69$ & $5.40 \pm 0.40$ \\
\hline Gastroenterology & $15.52 \pm 0.64$ & $4.25 \pm 0.24$ \\
\hline Pulmonology & $17.04 \pm 0.42$ & $6.42 \pm 0.18$ \\
\hline Pediatrics & $15.76 \pm 0.59$ & $4.99 \pm 0.41$ \\
\hline Internal & $15.00 \pm 0.70$ & $3.51 \pm 0.32$ \\
\hline Toxicology & $14.68 \pm 0.76$ & $3.43 \pm 0.18$ \\
\hline Dermatology & $15.28 \pm 0.64$ & $3.79 \pm 0.16$ \\
\hline Neurology & $15.68 \pm 0.67$ & $3.79 \pm 0.16$ \\
\hline General practitioner & $15.16 \pm 0.71$ & $3.40 \pm 0.13$ \\
\hline General surgery & $15.48 \pm 0.62$ & $4.22 \pm 0.44$ \\
\hline Infectious Disease & $15.24 \pm 0.72$ & $3.72 \pm 0.11$ \\
\hline Genetics & $15.36 \pm 0.50$ & $4.34 \pm 0.15$ \\
\hline Orthopedics & $15.72 \pm 0.45$ & $6.20 \pm 0.20$ \\
\hline Hematology & $15.52 \pm 0.63$ & $4.16 \pm 0.25$ \\
\hline Ophthalmology & $15.40 \pm 0.41$ & $6.11 \pm 0.28$ \\
\hline Neurosurgery & $15.60 \pm 0.66$ & $4.18 \pm 0.17$ \\
\hline Psychiatry & $17.28 \pm 0.51$ & $8.61 \pm 0.37$ \\
\hline Obstetrics and Gynecology & $16.00 \pm 0.63$ & $4.59 \pm 0.22$ \\
\hline Cardiovascular Surgery & $16.88 \pm 0.74$ & $5.62 \pm 0.16$ \\
\hline Total Mean & $15.92 \pm 0.14$ & $4.88 \pm 0.12$ \\
\hline
\end{tabular}

In this study, the total mean of examination time and commitment to prescription principles was $4.88 \pm 0.12$ min and $15.92 \pm 1.14$, respectively.

For data analysis, at first, Pearson correlation was computed between research variables for outpatients' examination time and physicians' prescription quality. The results of correlation coefficient are presented in Table 3.

Table 3. Pierson correlation coefficients between outpatients' Examination time and physicians' prescription quality variables

\begin{tabular}{|c|c|c|c|c|c|c|c|}
\hline & & Legibility & $\begin{array}{l}\text { Pharmaceutical } \\
\text { form }\end{array}$ & $\begin{array}{l}\text { Medical } \\
\text { order }\end{array}$ & $\begin{array}{l}\text { Physician } \\
\text { identifying } \\
\text { information }\end{array}$ & $\begin{array}{l}\text { Patient } \\
\text { identifying } \\
\text { information }\end{array}$ & $\begin{array}{l}\text { Total } \\
\text { quality } \\
\text { prescription }\end{array}$ \\
\hline \multirow{2}{*}{$\begin{array}{l}\text { Examination } \\
\text { time }\end{array}$} & $\begin{array}{l}\text { Pearson } \\
\text { Correlation }\end{array}$ & 0.121 & 0.292 & 0.235 & 0.013 & 0.054 & 0.329 \\
\hline & P-value & 0.005 & 0.0001 & 0.0001 & 0.755 & 0.208 & 0.0001 \\
\hline
\end{tabular}

As shown in Table 1, correlation coefficients between outpatients' examination time and dimensions of "legibility", "pharmaceutical form" and "medical orders", and the total quality of prescription were significant 
( $\mathrm{p}$ 0.005). It means that there was a positive correlation between outpatients' examination time and the dimensions of prescription quality. Also, correlation coefficients between outpatients' examination time and dimensions of "physician identifying information" and "patient identifying information" were not significant ( $\mathrm{p}$ 0.208). It means that there was no correlation between outpatients' examination time and these dimensions of prescription quality.

The correlation coefficient between outpatients' examination time and physicians' prescription quality variables were positive. Hence, this relationship was direct, and with increasing examination time, physicians' prescription quality increased. To estimate the effect of increased examination time on physicians' prescription quality, a linear regression model was used.

Table 4. Linear regression model between outpatients' Examination time and physicians' prescription quality variables

\begin{tabular}{llllll}
\hline \multirow{2}{*}{ Model } & \multicolumn{2}{l}{ Unstandardized Coefficients } & Standardized Coefficients & & Sig. \\
\cline { 2 - 4 } & B & Std. Error & Beta & & \\
\hline (Constant) & 14.002 & .245 & - & 57.251 & .0001 \\
Examination time & .393 & .048 & .329 & 8.163 & .0001 \\
\hline
\end{tabular}

As shown in the above table, the relationship between outpatients' and physicians' prescription quality variables is as follows:

$$
\mathrm{P}=0.329 \mathrm{~T}
$$

T: added examination time, $\mathrm{P}$ : added prescription quality

According to the formula above, increase per minute in patient's examination by a physician, which is about 0.4 points, was added to the basic quality scores of prescription.

This formula shows that adding each minute to patient's examination time by a physician, will add about 0.33 points to the basic quality scores of prescription.

\section{Discussion}

The drug mean per prescription was 3.48. The World Health Organization has defined 1.5 drugs as the standard number per prescription; while the drug mean per prescription is 3.5 in Iran (Kazemzadeh, Hamedi, \& Banejad Janatti, 2013; Zeraati et al., 2014). Rashidi and Afkhamzadeh (2010) and Safaeian et al. (2011) reported that drug mean per prescription was 2.7 and 2.1, respectively, which is different from the results of this study (Rashidi \& Afkhamzadeh, 2012; Safaeian, Kebriaeezadeh, Hashemi-Fesharaki, \& Salami, 2014). Also, in Dolatabadi and Jalili's (2008) study, drug mean was 3.22 which is approximately at par with the results of this study (Dolatabadi \& Jalili, 2009). The results showed that errors rate was high, as a result of the large number of prescribed drugs (Sadeghian, Safaeian, Mahdanian, Salami, \& Kebriaee-Zadeh, 2013).

As shown in the present study, $73.30 \%$ of prescriptions were legible. In a study conducted by Motamed et al. (2006) and Safaeian et al. (2011), 90 and 16\% of prescriptions, respectively, were not approved, which is contrary to the results of this study (Kazemzadeh et al., 2013; Sadeghian et al., 2013). The results of the current research are compatible with the previous research (Serveh et al., 2013); in this study, 68.2\% of prescriptions were legible (Parang, Golmakani, Movaffaq, \& Jafari Sani, 2014). To avoid errors of prescriptions illegibility, the use of electronic prescription was proposed (Shah et al., 2001).

The results of this study showed that 53.82 of the prescriptions had correct pharmaceutical form (the number of drugs: 49.22\%; drug dosage: 50\%; order of drug use in Latin: $64.81 \%$ ). The results of the current research are compatible with that of Zeraati et al. (2012) who reported that $37.7 \%$ of the prescriptions written in teaching hospitals and 49.2\% in non-teaching hospitals were legible (Zeraati et al., 2014). Perwitasari et al. (2007) reported that the correct name of the drug was written in $93.89 \%$ of the prescriptions (Perwitasari, Abror, \& Wahyuningsih, 2010), while Heidari et al. (2012) reported that the complete name of the drug was written in $86.2 \%$ of the prescriptions and they are incompatible with the results of the current research (Heidari, Khodadadi, Ravari, Asadi, \& Fatehi, 2012). Lack of integrity in clinical pharmacology education and insufficient prescriptions practice during the academic course is the main cause of these errors (Zare, Razm Jou, Ghaemi Nia, Zeyghami, \& Agha Maleki, 2008). 
The results of this study showed that $66.07 \%$ of the prescriptions had correct medical orders (the number of drugs: $58.39 \%$; drug dosage: $66.53 \%$; the order of drug use in Latin: $43.33 \%$; medical recommendations: 40.82 ; duration of drug use: 92.18; instruction for drug use: 83.53; drug use frequency: 80.87). In a study by Rashidi and Afkhamzadeh (2010), number of drugs, drug dosage, the order of drug use and duration of drug use were written in 44.1, 34.4, 70.3 and $41.8 \%$ of prescriptions, respectively (Rashidi \& Afkhamzadeh, 2012). Perwitasari et al. (2007) reported that $0.88 \%$ of prescriptions had no medical recommendations (Perwitasari et al., 2010). In a study conducted by Wingert et al. (2002), 95\% of the prescriptions had incomplete drug dosage (Wingert, Chan, Stewart, Lawrence, \& Portnoy, 1975). Physicians made prescription errors as a result of boredom, haste, lack of knowledge and skills in using drugs (Heaton, Webb, \& Maxwell, 2008; Valizadeh, Ghasemi, Nagafi, Delfan, \& Mohsenzadeh, 2008).

In $98.08 \%$ of the examined prescriptions in the present study, physician's identifying information was mentioned (name, family name, specialty and medical system code: 100\%; signature: 94\%). Serveh et al. (2013) reported that 7.7 and $28 \%$ of the prescriptions had no physician's name and signature, respectively (Parang et al., 2014). In their study, Perwitasari et al. (2007) reported that the physician's name was written in $93.45 \%$ of the prescriptions (Perwitasari et al., 2010). According to the existing insurance regulations in Iran, if the physician's name and signature are not included in a prescription, the prescription is subject to medication deduction. Thus, physicians usually append their signatures on their prescriptions. The existence of this control system can explain the obtained high percentage of physician's identity information in this study.

The results revealed that in $80.36 \%$ of the examined prescriptions, patient's identifying information were written (name, family name, age and gender: $100 \%$; weight: $1.8 \%$ ). In a study by Serveh et al. (2013), patient's name, age and gender were written in 36.6, 2.9 and 1.8\% of the prescriptions, respectively (Parang et al., 2014). Perwitasari et al. (2007) showed that the patient's name, age and weight were written in 99.56, 47.60 and $1.31 \%$ of the prescriptions, respectively (Perwitasari et al., 2010). In a study conducted by Neupane and Ansari (2009), there were no errors in writing patient's gender and age (Ansari \& Neupane, 2009). The specific form of health care insurance booklets in which patient's first name, last name, age and gender were previously printed by the insurance companies might be the cause of this result.

The results of this study showed that the highest and lowest mean of prescriptions quality was related to the psychiatrist (17.28 \pm 1.24$)$ and toxicologist (14.68 \pm 1.84$)$, respectively. Zeraati et al. (2012) reported on the highest and lowest mean of prescriptions quality in teaching hospitals with regards to neurosurgery and emergency medicine and in non-teaching hospitals with regards to cardiovascular and general surgery, respectively (Zeraati et al., 2014).

Also, the total mean of examination time was $4.88 \pm 1.40$ min. Evaluating examination time of 22 specialists which determined the highest and lowest mean of outpatients' examination time were related to the psychiatrist $(8.61 \mathrm{~min})$ and general practitioner $(3.40 \mathrm{~min})$, respectively. Mosadeghrad (2003) reported examination time to be $5.6 \mathrm{~min}$, after participatory management training (Mosadeghrad, 2004). The study of Benson and Burnet (2000) showed that specialists of clinics devoted $37 \mathrm{~min}$ to new patients and $29 \mathrm{~min}$ to re-visiting patients, which is moderate. Also, in public clinics, physicians spent 23 min for new patients (Benson \& Burnet, 2001). In the study of Aaeenparast et al. (Ayinparast, Tabibi, Shahanaqi, \& Arianajad, 2009), total mean of examination time was $3.92 \mathrm{~min}$. The standard of examination time in the first year of the Health Sector Evolution Guideline implementation was 8 patients per hour for all physicians and 6 patients per hour for psychiatrists in government hospitals; and in the second year of implementation in 2015, it was 15 min for the general practitioner, 20 min for specialist, $25 \mathrm{~min}$ for specialty and $30 \mathrm{~min}$ for psychiatrist per patient as declared (Javadi, Khui, Solaimani, \& Gholami, 2008).

Pearson correlation test between outpatients' examination time and dimensions of "legibility", "pharmaceutical form" and "medical order", and the total quality of prescription was significant $(\mathrm{p}<0.005)$. Also, it was not significant between outpatients' examination time and dimensions of "physicians' identifying information" and "patients' identifying information" ( $p>0.208)$. The requirement of doctors to stamp insurance booklets by the insurance companies and printing of patients' identifying information in their pages might be the cause of no relationship.

After fitting the regression model, a linear relationship was confirmed, so that with increase per minute during the patient examination time with a physician, about 4.0 points were added to the basic quality scores of prescription. Bayati et al. (2004) did not find a relationship between examination time and physician's skill (Bayati et al., 2011). In a study was conducted among nurses, they said by devoting more time to reports writing, 50 percent of prescription errors was reduced (Attarzadeh Behbahani, Yaghmaei, \& Akhtardanesh, 2012). It 
seems that some factors such as a large number of patients, consulting patients together, and physician's interest in consulting all patients as soon as possible played an important role in reducing the examination time per patient. In this study, examination time was less than the standard consulting time and these factors may have an important role in uncertain disease diagnosis (Ranjbar Ezzatabadi et al., 2014).

Undoubtedly, commitment to standard prescription principles by physicians increase the likelihood of proper treatment, its effectiveness and patients' improvement (Zeraati et al., 2014). Long examination time reduces the probability of prescription and medication errors by the physician (Hughes, 1983). Hence, using a telephone or internet reservation at clinics, developing a specific working schedule for physicians, increasing physicians' working shift in clinics, increasing the number of physicians in government hospitals and giving priority to reception of special patients can improve examination time (Ranjbar Ezzatabadi et al., 2014). Commitment to standard examination time makes the physician to spend more time in writing the ideal prescription. Drug and drug-based system is a complex and multi-factorial issue and solving its defect and problems require national will and consideration of statesmen, health and practitioners of other involved organizations.

\section{Conclusion}

In this study, there was a significant relationship between outpatients' examination time and three dimensions of prescription with lower scores (legibility, pharmaceutical form and medical order), and a linear relationship was observed between outpatients' examination time and prescription quality. The current study was conducted in Ahvaz teaching hospitals, it is proposed that similar studies should be conducted in other hospitals. Further, the authors proposed to design a new checklist to assess prescription, because the quality prescription score was falsely higher due to the special format of the insurance booklet (requiring doctors to stamp insurance booklets and print patient's identifying information in insurance booklets). Considering commitment to standard prescription principles, examination time, which was declared by the Health Sector Evolution Guideline, improved physicians' prescription quality and the quality of provided services in hospitals. Therefore, providing an internet schedule for examination will be extremely helpful in organizing physicians' examination.

\section{Acknowledgments}

It is a pleasure to thank all the patients participated in our study. This study was supported by the Student Research Committee of Ahvaz Jundishapur University of Medical Sciences.

\section{Conflict of Interest}

The authors declare that there is no conflict of interests regarding the publication of this paper.

\section{References}

Ansari, M., \& Neupane, D. (2009). Study on determination of errors in prescription writing: A semi-electronic perspective. Kathmandu University Medical Journal, 7(3), 238-241. http://dx.doi.org/10.3126/kumj.v7i3.2730

Attarzadeh Behbahani, S., Yaghmaei, F., \& Akhtardanesh, N. (2012). Development and psychometric evaluation 'nurse satisfaction of report writing scale'. Journal of Health Promotion Management, 1(2), 54-65.

Ayinparast, A., Tabibi, J., Shahanaqi, K., \& Arianajad, M. (2009). Outpatient waiting time with the use of simulation models. Payesh Research Journal, 8(4), 327- 333.

Bayati, A., Soltanian, F., Kamali, P., \& Shamsi, M. (2011). Influencing factors on relative value unit of GPs'visits in private medical offices in Tehran. Hakim Research Journal, 14(2), 89-95.

Benson, R., \& Burnet, N. (2001). An audit of clinic consultation times in a cancer center. Clin Oncol, 13(2), 43-138.

Bobb, A., Gleason, K., Husch, M., Feinglass, J., Yarnold, P., \& Noskin, G. (2004). The epidemiology of prescribing errors:the potential impact of computerized prescriber order entry. Arch Intern Med, 164, 785-792. http://dx.doi.org/10.1001/archinte.164.7.785

Campbell, J. L., Ramsay, J., \& Green, J. (2001). Practice size: impact on consultation length, workload, and patient assessment of care. British Journal of General Practice, 51(469), 644-650.

Dolatabadi, M., \& Jalili, R. H. (2009). Patterns of physicians'drug prehlion in Sabzevar Iran 2008. Quarterly Journal of Sabzevar University of Medical Sciences, 16(3), 161-166.

Ford, R. C., Bach, S. A., \& Fottler, M. D. (1997). Methods of measuring patient satisfaction in health care $\begin{array}{lllll}\text { organizations. Health } \quad \text { Care } & \text { Management }\end{array}$ http://dx.doi.org/10.1097/00004010-199704000-00009 
Heaton, A., Webb, D. J., \& Maxwell, S. R. (2008). Undergraduate preparation for prescribing: the views of 2413 UK medical students and recent graduates. British Journal of Clinical Pharmacology, 66(1), 128-134. http://dx.doi.org/10.1111/j.1365-2125.2008.03197.x

Heidari, S., Khodadadi, A., Ravari, A., Asadi, G., \& Fatehi, Z. (2012). Prescription quality of medication chart of hospitalized patients in hospitals affiliated with Rafsanjan University of Medical Sciences, 2007. Journal of Rafsanjan University of Medical Sciences, 11(5), 437-448.

Hughes, D. (1983). Consultation length and outcome in two group general practices. British Journal of General Practice, 33(248), 143-147.

Javadi, M., Khui, H., Solaimani, F., \& Gholami, K. (2008). Rational prescription of drug (1st ed.). Tehran, Iran: Andishe Mandegar.

Jeddi, M. R., Jeddi, F. R., \& Mofrad, M. R. R. (2011). Physicians' commitment to principles of prescription writing for outpatients insured by medical services insurance organization in Kashan. Director General, $8(4), 544$.

Kazemzadeh, G. H., Hamedi, A., \& BanejadJanatti, F. (2013). Evaluating the impact of education via pamphlet on the medication errors of last year medical students. Medical Journal of Mashhad University of Medical Sciences, 56(4), 204-210.

Khouri, V., Changizi, S., Pourreza, A., \& Zeinali, R. (2009). General physicians' consultation time average and its effective factors in Gorgan. Payesh Research Journal, 8(1), 39-47.

Ladhari, R. (2009). A review of twenty years of SERVQUAL research. International Journal of Quality and Service Sciences, 1(2), 172-198. http://dx.doi.org/10.1108/17566690910971445

Mosadeghrad, A. (2004). The role of participative management in outpatients'waiting time, visit time and satisfaction at Razi hospital, Qazvin, Iran (2002). Hakim Research Journal, 7(3), 14-23.

Motamed, N., Kashi, Z., Saffar, M., Alian, S., Khademloo, M., \& Eslamian, R. (2006). Consideration of prescribing ability of 10 prevalent diseases with OSCE method in Sari Medical Science University interns in 2004. Journal of Mazandaran University of Medical Sciences, 16(51), 101-110.

Parang, S., Golmakani, N., Movaffaq, G., \& Jafari Sani, H. (2014). Prescription writing errors of midwifery students in common gynecological problems. Journal of Midwifery and Reproductive Health, 2(2), 105-111.

Perwitasari, D. A., Abror, J., \& Wahyuningsih, I. (2010). Medication errors in outpatients of a government hospital in Yogyakarta Indonesia. International Journal of Pharmaceutical Sciences Research and Review, $1(1), 8-10$.

Ranjbar Ezzatabadi, M., Bahrami, M., Sadeghi, J., Moradi, M., Masoomi, R., Baghiyani, N., \& Hadizade, F. (2014). Estimate the average waiting time to receive service in the outpatient department: a case study on Shahid Rahnemoon and Afshar Clinics in Yazd, Iran. Journal of School Health, Yazd, 13(1), 30-39.

Rashidi, K., \& Afkhamzadeh, R. (2012). Assessing young and trainig doctors' prescription ability in Kordestan Province. Strides in Development of Medical Education, 10(1), 42-49.

Sadeghian, G.-H., Safaeian, L., Mahdanian, A.-R., Salami, S., \& Kebriaee-Zadeh, J. (2013). Prescribing quality in medical specialists in Isfahan, Iran. Iranian journal of pharmaceutical research: IJPR, 12(1), 235.

Safaeian, L., Kebriaeezadeh, J., Hashemi-Fesharaki, M., \& Salami, S. (2014). Assessing the prescription writing principles in medical students' prescriptions during internship. Journal of Isfahan Medical School, 32(277), 282-291.

Shadpour, K. (2006). Health sector reform in Islamic Republic of Iran. Hakim Research Journal, 9(3), 1-18.

Shah, S. N. H., Aslam, M., \& Avery, A. J. (2001). A survey of prescription errors in general practice. Pharmaceutical Journal, 267(7178), 860-862.

Tabibi, J., Gohari, M., Shahri, S., \& Aghababa, S. (2011). Assessment of health care services in outpatient clinics based on SERVQUAL model in hospitals of Tehran. Journal of Tehran Faculty of Premedical, 5(4), 49-57.

Valizadeh, F., Ghasemi, S.-F., Nagafi, S.-S., Delfan, B., \& Mohsenzadeh, A. (2008). Errors in medication orders and the nursing staff's reports in medical notes of children. Iranian Journal of Pediatrics, 18(1), 33-40.

Wingert, W. A., Chan, L. S., Stewart, K., Lawrence, L., \& Portnoy, B. (1975). A study of the quality of prescriptions issued in a busy pediatric emergency room. Public Health Reports, 90(5), 402. 
Zare, N., Razm Jou, M., Ghaemi Nia, M., Zeyghami, B., \& Agha Maleki, Z. (2008). Effectiveness of the feedback and recalling education on quality of prescription by general practitioners in Shiraz.

Zeraati, F., Araghchian, F., Esna'Ashari, F., Saneii, A., \& Torkashevand, E. (2014). The comparison between observance of prescribing principles in Hamadan University of Medical Sciences teaching staff and non-teaching staff in 2012. Scientific Journal of Hamadan University of Medical Sciences, 21(1), 66-71.

\section{Copyrights}

Copyright for this article is retained by the author(s), with first publication rights granted to the journal.

This is an open-access article distributed under the terms and conditions of the Creative Commons Attribution license (http://creativecommons.org/licenses/by/3.0/). 